\title{
Obamacare accelerating into prime time
}

$\mathrm{U}$ S President Barack Obama's health care law has survived dozens of attempts in Congress to strangle it, several elections fought over it and one big Supreme Court decision, but is now facing challenges from within.

The stumbling debut of HealthCare.gov, the law's gateway to subsidized health insurance for millions, and associated problems have shaken confidence in "Obamacare" in ways Republican opponents could not achieve in three years of trying. And this is happening as the law finally accelerates into prime time.

Starting in 2014, nearly all Americans must carry health insurance or face a fine. No longer can they be denied coverage or charged exorbitantly because of existing or past maladies. The law confronts head-on what almost everyone agrees is the central shame of American health care: skyhigh medical bills driving people into poverty or away from crucial treatment.

A complex system of subsidies, consumer protections and marketplace innovations is taking shape, all with the goal of making coverage within reach of everyone. One key to the law's expanded coverage is a network of health insurance "exchanges" that opened in every state in October, offering plans starting Jan. 1 to people who don't get coverage from employers. The federal government is running most of the exchanges because only 14 states agreed to do it themselves.

The federal launch was a bust, thwarting multitudes who tried to enrol on the bug-infested HealthCare.gov website even as time has grown short to obtain insurance before the individualcoverage mandate kicks in. Now, however, the site is finally on the mend.

The government reported on Dec. 11 that close to 365000 people enrolled for private coverage in federal and state exchanges in October and November. Though far short of the 1.2 million who were expected to sign up, the statistics

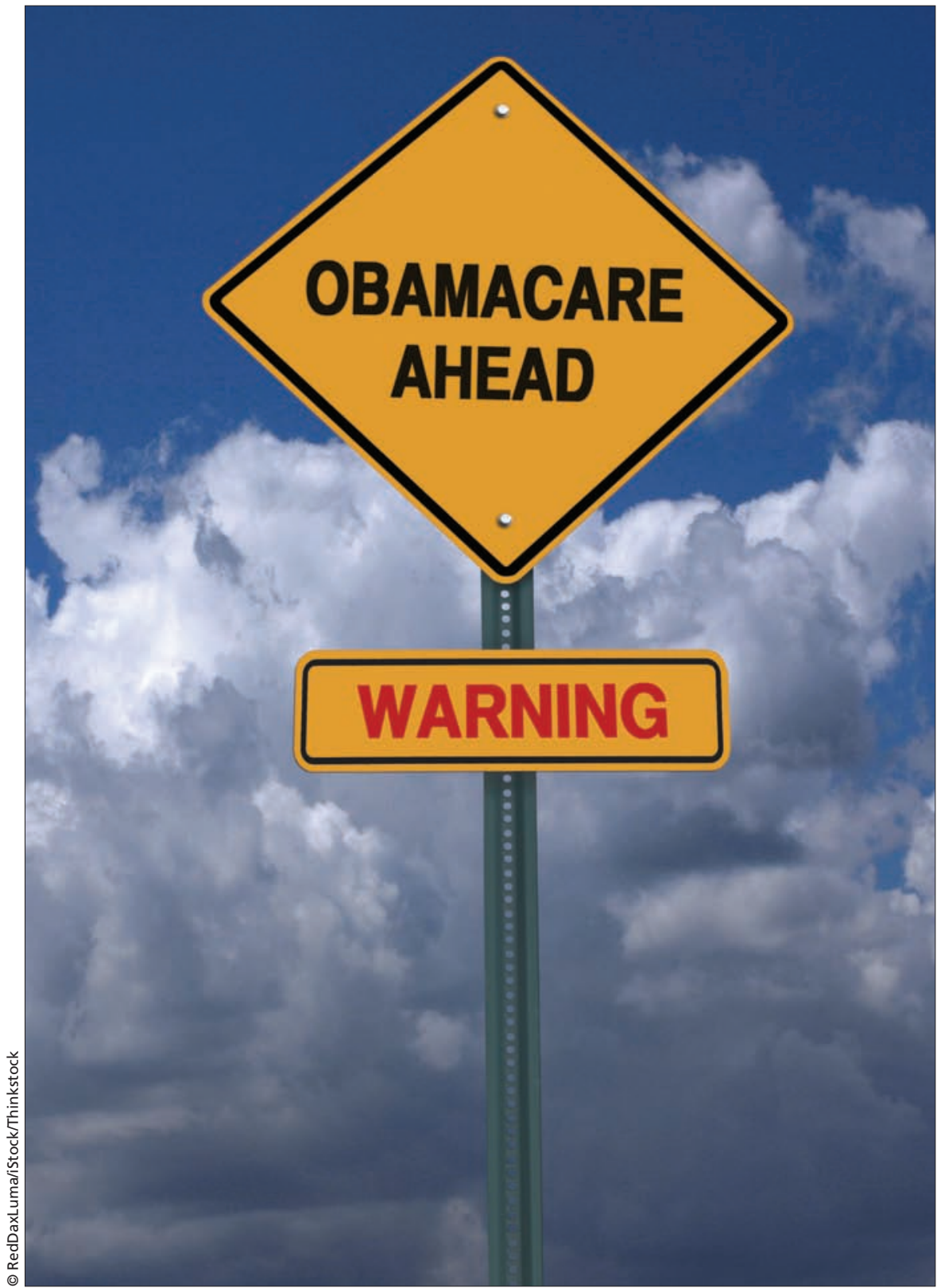

The stumbling debut of HealthCare.gov and associated tribulations have shaken confidence in "Obamacare" in ways Republican opponents could not achieve in three years of trying.

nevertheless indicate that the bottleneck in the federal website is easing.

At the same time, more than 4 million people who carried bare-bones coverage got cancellation notices because their policies didn't meet new federal standards and insurers chose to drop rather than improve those plans.
The government switched gears and allowed reinstatement of these substandard policies for one more year, although it's not clear how many insurers are following through. People who lose coverage can go to an exchange and, provided they can successfully navigate it, get a better plan. 
Obama's sales pitch all along has been that the Patient Protection and Affordable Care Act would leave everything intact for those who are happy with what they have. "If you like your doctor, you will be able to keep your doctor, period," he told the American Medical Association in 2009. "If you like your health care plan, you'll be able to keep your health care plan, period."

Obama was not able to keep that promise and has been by turns contrite about the problems and defiant about the broad strokes of his signature law. "We believe that in America, nobody should have to worry about going broke because somebody in their family or they got sick," he said in December. "If I have to fight another three years to make sure this law works, then that's what I'll do."

But Obama will have his hands full restoring his credibility, getting Ameri- cans to believe in reforms they've always been nervous about and protecting fellow Democrats from political backlash, says Robert Blendon, an authority on health policies and politics at the Harvard School of Public Health in Boston, Massachusetts.

"He has to turn around the incredible national mood about what happened in the failure to launch," he says.

Blendon sees neither party representing the middle ground of public opinion. People seem to want the law scaled back, a nonstarter with Obama, but they don't want it repealed, which would be the Republican approach.

Another major component of the law, a mandate that larger employers offer insurance to workers or pay penalties, was delayed by a year. Also set aside for a year: access to the exchanges by small businesses, which can still get subsidized coverage for workers but not through the portals that were supposed to make it easy.

More challenges loom. Chief among them is whether young, healthy people - the hardest sell on health insurance — will sign up in sufficient numbers in 2014 to offset the costs of caring for older or sicker policyholders coming into the insurance stream. If not, premiums could spike the next year. "The real explosive potential will come if rates start going up in 2015 because of skewed enrollment," says Blendon.

One element of the law, though, has been unfolding relatively smoothly. Medicaid, the government insurance system for the poor, has been extended to people of greater income in 25 states. Applications jumped $16 \%$ in the first month alone. - Cal Woodward, Washington, DC

CMAJ 2014. DOI:10.1503/cmaj.109-4680 